Briggs, M. (1953). J. gen. Microbiol. 9, 234-248

\title{
The Classification of Lactobacilli by means of Physiological Tests
}

\author{
BY MARY BRIGGS \\ National Institute for Research in Dairying, \\ University of Reading
}

SUMMARY: Four hundred and fifty-two strains of lactobacilli, including representatives of all recognized species and 197 freshly isolated cultures, were studied. It was possible to classify $390(86 \cdot 3 \%)$ of these into eight groups on the basis of the results of six physiological tests. The tests used were the production of gas from glucose and citrate, and of ammonia from arginine, growth at 15,45 and $48^{\circ}$, heat survival at 60 and $65^{\circ}$ and tolerance of 4,6 and $8 \%(w / v)$ sodium chloride.

The widespread habitat of organisms of the genus Lactobacillus and their importance in dairy, industrial and fermentation processes, have occasioned considerable interest for many years. Since the first reports in the literature at the end of the nineteenth century, many papers have been published dealing with the characteristics of the various species and their differentiation, but few workers have attempted a classification of all members of this genus. The existing groups have been incompletely described and characterized, so that it has been virtually impossible to identify strains of lactobacilli isolated from new sources. Such strains have frequently been given the status of new species and named accordingly. Although some workers have examined and correlated certain of these species, much confusion still exists.

Most of the earlier workers were interested in the organisms isolated from milk, the human intestine and faeces; differences in colonial and morphological appearances and in the fermentations of various sugars were the differential tests most commonly used. The distinction between Lactobacillus acidophilus, a homofermentative intestinal organism first described by Moro (1900), and various other lactic acid bacteria has been studied by many workers. Weiss \& Rettger (1934) found many similarities between $L$. acidophilus and another intestinal organism, $L$. bifidus, isolated by Tissier (1900) from the faeces of breast-fed infants, but Orla-Jensen, S., Orla-Jensen, A. D. \& Winther (1935-6) considered these two organisms to be different; recently Friedman \& Black (1941) have supported this view. Various reports describe the identification of $L$. bulgaricus, first isolated by Grigoroff (1905) from fermented milk, but the evidence is still not convincing. Heinemann \& Hefferan (1909) suggested that $L$. bulgaricus was a synonym for $L$. acidophilus, but Rahe (1918) and Kulp \& Rettger (1924) maintained that these organisms could be separated on the basis of sugar fermentations. Kulp (1929), Curran, Rogers \& Whittier (1933) and Sherman \& Hodge (1940) reported distinct differences between the two organisms.

For many years the organisms found in dental caries were thought to belong to a distinct species, but Howe \& Hatch (1917) suggested that these organisms 
were lactic acid bacteria similar to the Moro-Tissier group. However, McIntosh, James \& Lazarus-Barlow (1922, 1924) considered them to be a separate group and named them Bacillus acidophilus-odontolyticus. Rosebury, Linton \& Buchbinder (1929) and Hadley, Bunting \& Delves (1930) found little difference between dental caries organisms and $L$. acidophilus, but Morishito (1929) separated them by using sugar fermentation reactions. Very few intensive studies of the differences between other homofermentative lactobacilli have been undertaken, although Sherwood (1939) reported that $L$. casei was morphologically different from $\boldsymbol{L}$. plantarum and also produced more acid, and Burri \& Kollman (1941) suggested that growth at $51^{\circ}$ and $20^{\circ}$ distinguished $\boldsymbol{L}$. lactis from $\boldsymbol{L}$. helveticus. The gas-producing species of lactobacilli include numerous variously named organisms, many of which are probably identical. The most important investigations of this group were made by Pederson (1938), who divided it into four sections on the basis of correlation between growth temperatures and sugar fermentations, and by Shimwell (1948), who used similar characteristics in his classification of the brewery lactobacilli, which include both homo- and heterofermentative organisms.

In his classic work, Orla-Jensen (1919) was the first to study the complete family Lactobacteriaceae. From the results of this and subsequent work, Orla-Jensen $(1942,1943)$ divided the catalase-negative rods (genus Lactobacillus) into three groups, the high- and low-temperature homofermentative groups which are named Thermobacterium and Streptobacterium respectively, and a heterofermentative group which he called Betabacterium. The organisms within these groups were mainly subdivided by means of the optical rotation of the lactic acid produced, sugar fermentations and the quantity of acid formed in milk. Although this classification was a great improvement on all earlier attempts, it was not completely satisfactory as a considerable number of intermediate and unclassifiable organisms was found.

The organisms of the genus Lactobacillus Beijerinck, included in the family Lactobacteriaceae Orla-Jensen, are described by Pederson (1948) (in Bergey's Manual of Determinative Bacteriology, 1948) as Gram-positive rods which ferment carbohydrates and polyalcohols either by homofermentation to lactic acid or by heterofermentation to lactic and acetic acids, alcohols and carbon dioxide. They are catalase-negative, microaerophilic, non-motile and do not produce spores; they do not reduce nitrate to nitrite, liquefy gelatin or grow on potato.

The classification of lactobacilli by Pederson in Bergey's Manual (1948) is largely based on Orla-Jensen's work, but the descriptions of the various organisms are supplemented by observations of other workers. The homofermentative group is subdivided by tests similar to those described by OrlaJensen, and the heterofermentative species according to Pederson (1938); although this appears admirable in theory, it is found to have distinct practical limitations. For some species, such as $L$. acidophilus and $L$. helveticus, no differentiating characteristics are quoted, but perhaps the most serious criticism concerns the variability of many of the distinguishing reactions described. Sugar fermentations, for example, have been found unreliable in 
that they have frequently failed to give consistent and reproducible results, not only in the hands of different workers, but also with the same individual on different occasions (Weaver, 1932). The optimum temperature of growth for a given organism is a vague characteristic depending on many factors such as the medium used and the vigour of the particular culture. It is a characteristic difficult to determine accurately within a given range, yet Bergey's Manual suggests a subdivision of the heterofermentative lactobacilli based largely on the difference between optimum temperatures of $28-\mathbf{3 2}^{\circ}$ for one group and $35-40^{\circ}$ for the other. The time and labour involved in the determination of the optical rotation of lactic acid is a serious drawback to the use of this test for purposes of differentiation.

The type species of the genus is $L$. caucasicus Beijerinck. This organism was isolated from kefir by Beijerinck (1889) and is of considerable historical interest, but its early description lacks detail and no worker recently has succeeded in isolating a similar organism from kefir. The lactobacillus now found in kefir is a heterofermentative organism named Betabacterium caucasicum by Orla-Jensen and confusion exists between this organism and the homofermentative type species, $L$. caucasicus. Tittsler, Geib \& Rogosa (1947) suggested a system of classification based on a correlation of physiological and biochemical tests, but although the preliminary account of this work appeared promising, no details have yet been published. An account of a symposium on the lactic acid bacteria containing considerable information of a general nature has been published recently (Tittsler, Pederson, Snell, Hendlin \& Niven, 1952). A complete review of the relevant literature is beyond the scope of this paper, but the few references quoted show that there is much conflicting, contradictory and unreliable evidence. Reference to the number of organisms included in Appendix I of the list in Bergey's Manual (pp. 361-4) will leave no doubt that further investigation of the genus Lactobacillus is necessary.

The object of the present work was to establish simple, reproducible and reliable tests for the differentiation and characterization of the lactobacilli. Examination of the literature indicated that much of the contradictory evidence reported might be traced to the use, in the same tests, of different media by various workers. As a preliminary to this work, a standard basal medium was evolved (Briggs, 1953) in which all strains of lactobacilli grew well, so that valid comparisons could be made.

\section{METHODS}

\section{Cultures used}

A collection of some 100 strains of lactobacilli has been maintained at this Institute for many years and these cultures were used during the preliminary trials of various physiological tests. It was found possible to group these organisms by means of six tests which are described below. Additional named strains were then obtained from many different collections so that further representatives of all groups could be tested similarly. Finally, strains of 
freshly isolated lactobacilli from different sources were tested to determine whether these also could be grouped in the same way. Before the strains were transferred to stock and subsequently tested, single colonies were picked, the resulting cultures tested for catalase production and a note was made of the colony forms, morphological appearances and Gram-reactions. A list of the 452 cultures included in the final collection with the total numbers of each 'species' or set of cultures and the appropriate code numbers is shown in Table 1.

Several representatives of certain named strains are included; these were obtained from different sources and all were tested to determine whether the effects of various methods of maintenance had affected their specific reactions.

\section{Media}

Storage. Stock cultures were stored at $4^{\circ}$ in yeast glucose litmus milk plus chalk (Davis, 1935) and renewed every 3 months. A minimum of four transfers was made in yeast glucose litmus milk before the cultures were incubated in yeast glucose litmus milk plus chalk and replaced in the refrigerator.

Broth and agar media. The composition of the tomato glucose broth used throughout this work was : tomato juice, $10 \mathrm{ml}$.; Neopeptone (Difco), $1.5 \mathrm{~g}$.; glucose, 2 g.; sodium chloride, $\mathbf{0 . 5}$ g.; Tween 80 (polyoxyethylene sorbitan monooleate), $0.1 \mathrm{ml}$.; Yeastrel, $0.6 \mathrm{~g}$.; soluble starch, $0.05 \mathrm{~g}$.; distilled water to $100 \mathrm{ml}$. The $\mathrm{pH}$ value was adjusted to 6.8 and the medium was autoclaved at $15 \mathrm{lb}$./sq.in. for $20 \mathrm{~min}$. Further details of this medium have been given in an earlier paper (Briggs, 1953).

The tomato juice was prepared by adding $1 \mathrm{l}$. of distilled water to $12 \mathrm{lb}$. of tomatoes, mincing and then pulping in a metal press. The juice was filtered, neutralized to $\mathrm{pH} 7.0$ and autoclaved at $120^{\circ}$ for $15 \mathrm{~min}$. Ten ml. of this concentrated juice were equivalent to $40 \mathrm{ml}$. of the tomato juice prepared as previously described (Briggs, 1953). Tomato glucose agar, prepared by the addition of $2 \%$ agar to the above medium, was used for plating. The plates were incubated anaerobically in an atmosphere of $90 \%$ hydrogen $+10 \%(v / v)$ carbon dioxide.

All strains of lactobacilli grow well in the broth and in the agar media. Special media were necessary for the detection of gas production; tomato glucose broth was used, however, as the basal medium for all other physiological tests, in which growth was detected by observation of opacity, the uninoculated tomato glucose broth being translucent.

\section{Preparation of inoculum}

False negative results of any test may be obtained unless the organisms are growing vigorously before inoculation. Inocula were prepared from stock cultures which were subcultured into yeast glucose litmus milk for two transfers and then into tomato glucose broth for at least two further transfers. Some of the slower-growing organisms required three or four subcultures in broth before regaining their full vigour. An inoculum of two double standard 
Table 1. Named cultures or sources of lactobacilli and code numbers

Code no.*

A1-A22
AA1
AH1-AH 54A
AR1-AR5
B1-B23
BC1, BC2
BF1, BF3, BF4
BR1-BR 33
C1-C30
CC1
CD1-CD3
CP1-CP3
CS1-CS8

D1-D9
E1-E4
F1-F16
FG1
G1, G2
GF1, GF2
GORD
H1-H21
HL1
J1, J2
K1
KR1
L1-L19
LE2-LE6
LC1
M1
M6NO, MBP,
MM5, MP8, ME10
MF1
MR1-MR B
N1-N7

01-013

P1-P31

PF 1-PF7

PN1, PN2

PR 1-PR 11

PS 1

R1

RF 1

RM1

S1-S6

SL 1-SL50

SM 1-SM 10

St 1-St3

SM 1 A, S38 A,

S40A, S41 A

T1-T 16

TH1

U1

W1

WL1-WL45

X1-X4

$Y 1, Y 2$

YOG 1-YOG5

Y48, Y 48(1)

27, 126, 237,

504
Name† or source

L. acidophilus

L. acidophil-aerogenes

Lactobacillus species from Gruyère cheese

L. arabinosus

L. bulgaricus

L. buchneri

Lactobacillus species from infant faeces

Lactobacillus species from Stilton cheese

L. casei

L. caucasicus

Lactobacillus species from chick duodena

Lactobacillus species from New Zealand cheese

Lactobacillus species from dried stomachs of calves

L. delbrueckii

L. pentoaceticus

L. fermenti

L. frigidus

L. gayonii

Lactobacillus species from guinea-pig faeces

Lactobacillus species from pasteurized milk

L. helveticus

L. hilgardii

L. jugurt

Lactobacillus species from kefir

Lactobacillus species from sauerkraut

L. lactis

L. leichmannii

Lactobacillus species from fish silage

L. mannitopoeus

Lactobacillus species from calf abomasa

L. malefermentans

Lactobacillus species from raw milk

Lactobacillus species from pig and chick

caeca

$L$, odontolyticus and L. species of oral origin 13

L. plantarum

Lactobacillus species from pig faeces

L. pentosus

Lactobacillus species from présure

L. parous

L. brassicae-fermentatae

Lactobacillus species from rabbit faeces

Lactobacillus species from bovine rumen

L. bifidus

Lactobacillus species from silage

Lactobacillus species from Jugoslavian sour milk

Lactobacillus species from pig stomachs

Lactobacillus species from discoloured meat

L. pastorianus and L. species from beer

L. thermophilus

L. rudensis

Lactobacillus species from silage

Lactobacillus species from Sweden

L. brevis

L. lycopersici

Lactobacillus species from yoghourt

Lactobacillus species from Denmark

Lactobacillus species from pig intestines

* No. allotted to cultures when received.

$\dagger$ Name of culture as received.
No. of cultures

22

1

53

5

23

2

3

32

30

1

3

3

7

9

4

16

2

2

1

20

1

1

1

18

5

1

1

5

1

7

7

30

2

11

I

1

1

1

7

28

9

4

15

1

1

1

10

4

2

2

4 
(4 mm.) loopfuls of a $24 \mathrm{hr}$. culture into $10 \mathrm{ml}$. medium was used for all strains, except that with a few slow-growing varieties the same volume of inoculum from a $48 \mathrm{hr}$. culture was necessary.

\section{Incubation temperatures}

The incubation temperatures of the various species were chosen mainly on the basis of experience gained here in past years. Practical experience with individual cultures and reference to the temperatures used by other workers also influenced the choice. Strains received as $L$. lactis and $L$. thermophilus were incubated at $45^{\circ}$, strains of $L$. acidophilus, $L$. bulgaricus, $L$. delbrueckii, L. fermenti, L. helveticus and $L$. leichmannii at $37^{\circ}$, and strains of $L$. brevis, L. casei, L. pastorianus and L. plantarum at $30^{\circ}$.

\section{Physiological tests}

Production of gas from glucose. During a study of the sugar fermentation reactions of a few heterofermentative lactobacilli, it was noticed that no gas was produced in Durham tubes and that a more reliable method for testing the production of gas from glucose was required. The medium and technique of Gibson \& Abd-el-Malek (1945) was used successfully, cultures being incubated for 14 days.

Production of gas from citrate. A method for the determination of the production of gas from citrate was also described by Gibson \& Abd-el-Malek (1945). All the heterofermentative strains grew well and some produced gas in the citrate medium so that it was not considered necessary to supplement it with glucose as suggested by Gibson \& Abd-el-Malek. Cultures were incubated for 14 days.

Production of ammonia from arginine. Niven, Smiley \& Sherman (1942) reported a method for detecting the production of ammonia from arginine by streptococci. A modification of this method, in which tomato glucose broth was used as the basal medium, proved satisfactory for lactobacilli: $0.3 \%$ (w/v) L-arginine hydrochloride was added to tomato glucose broth before autoclaving; the same medium without arginine served as the control. Nessler's solution was used to test for the presence of ammonia after 14, days' incubation. It was necessary to read results immediately after the addition of the Nessler's solution as a greenish colour developed on standing. Determination of arginine hydrolysis by streptococci of known reaction gave identical results using the original and modified techniques.

Heat survival tests. Preliminary survival tests of a few strains at $60^{\circ}$ and $65^{\circ}$ for varying periods of time appeared promising. Heat survival tests of all cultures for 30,60 and 90 min. periods at these two temperatures were carried out in triplicate in a water-bath having an accuracy of $\pm 0.1^{\circ}$. Tubes of $10 \mathrm{ml}$. of tomato glucose broth were heated to the required temperature in the bath, nine tubes were removed, rapidly inoculated with the standard inoculum of each culture under test and then replaced in the bath. After allowing $2 \mathrm{~min}$. for the tubes to regain the temperature of the bath, three tubes were removed 
after $30 \mathrm{~min}$., three after $60 \mathrm{~min}$. and the remaining three after $90 \mathrm{~min}$. The tubes were cooled rapidly and incubated for 7 days. Inoculated controls were prepared by heating tubes in the bath and cooling to room temperature before inoculation. Investigation of a few strains indicated that testing at $65^{\circ}$ was unnecessary for cultures which did not survive $90 \mathrm{~min}$. at $60^{\circ}$.

Growth temperatures. A survey of the growth temperatures of ninety-five strains originally maintained here indicated that growth at $15^{\circ}, 45^{\circ}$ and $48^{\circ}$ could be used as differential tests. The accuracy of the water-bath used for the tests at $45^{\circ}$ and $48^{\circ}$ was $\pm 0 \cdot 1^{\circ}$ and the maximum variation of the $15^{\circ}$ waterbath was $0.5^{\circ}$. The standard inoculum was added to $10 \mathrm{ml}$. tomato glucose broth at the appropriate temperature. Cultures were incubated for 7 days at $45^{\circ}$ and $48^{\circ}$ and for 21 days at $15^{\circ}$.

Tolerance of sodium chloride. The growth of a few strains in broths containing $2,3,4,5,6,7$ or $8 \%(w / v)$ sodium chloride suggested that further investigation of the effects of 4,6 and $8 \%$ concentrations would prove helpful. Sodium chloride was added to tomato glucose broth (which contains $0.5 \% \mathrm{NaCl}$ ) to give the total salt concentration required. A standard inoculum of the culture to be tested was added to tubes of each of the three salt concentrations under test and also to a control tube of tomato glucose broth. Growth was observed during 14 days' incubation.

\section{RESULTS}

Four hundred and fifty-two cultures of lactobacilli were studied and 390 $(86.3 \%)$ of them were separated into eight groups on the basis of the results of the physiological tests. Forty-seven of the remaining sixty-two unclassified organisms were found to constitute three distinct sections; a fourth section accommodated the remaining fifteen organisms. The summarized reactions of the organisms of each group and section are shown in Table 2, with the exception of the miscellaneous strains in section 4. Certain tests have been omitted from the table, only those of direct importance in the separation of the groups being included. The remaining tests, which gave somewhat variable results, are mainly of confirmatory value.

\section{Organisms of group I}

Group I contained thirty-four strains including thirteen of the named L. acidophilus cultures (A1-A5, A 12-A17, A 20 and A22). Seven named strains of $L$. bulgaricus (B4, B7, B15, B16, B19, B20 and B23), one of L. delbrueckii (D2) and thirteen freshly-isolated strains (BF 4, CS2, N2, N4, N5, O13, PF 2, PF3, PF6, Y 48 (1), 27, 126 and 237) possessed the characteristic reactions of group I. Twelve of the freshly isolated cultures were of intestinal origin whilst the thirteenth $(013)$ was from a human mouth. Only two strains (A13 and A 15) produced gas from citrate and few organisms survived heating for $60 \mathrm{~min}$. at $60^{\circ}$. 


\section{Organisms of group II}

Only three named strains of $L$. acidophilus (A 18, A 19, A 21) and one of L. bulgaricus (of which duplicate cultures, B2 and B3, were tested) were included amongst the sixteen organisms in group II. The remaining eleven cultures (CS6, SM10, St1, St3, St5, WL1, WL2, WL7, WL12, Y 48, 504) were either unnamed or freshly isolated. No strains in this group produced gas from citrate and only $\mathrm{B2}$ survived heating for $60 \mathrm{~min}$. at $60^{\circ}$.

Table. 2. Summary of biochemical and physiological reactions of lactobacilli of each group and section

\begin{tabular}{|c|c|c|c|c|c|c|c|c|c|}
\hline \multirow[b]{3}{*}{ Group } & \multirow{3}{*}{$\begin{array}{c}\text { Gas } \\
\text { from } \\
\text { glucose }\end{array}$} & \multirow{3}{*}{$\begin{array}{c}\mathrm{NH}_{\mathbf{3}} \\
\text { from } \\
\text { arginine }\end{array}$} & \multicolumn{2}{|c|}{ Survivals at } & \multirow{2}{*}{\multicolumn{3}{|c|}{ Growth at }} & \multirow{3}{*}{$\begin{array}{c}\text { Tolerance } \\
\text { of } \\
4 \% \text { NaCl }\end{array}$} & \multirow{3}{*}{$\begin{array}{r}\text { No. } \\
\text { of stra } \\
\text { in gro }\end{array}$} \\
\hline & & & \multirow{2}{*}{$\begin{array}{l}60^{\circ} \text { for } \\
90 \text { min. }\end{array}$} & \multirow{2}{*}{$\begin{array}{l}65^{\circ} \text { for } \\
\mathbf{3 0} \text { min. }\end{array}$} & & & & & \\
\hline & & & & & $15^{\circ}$ & $45^{\circ}$ & $48^{\circ}$ & & \\
\hline I & - & - & - & - & - & + & - & - & $\mathbf{3 4}$ \\
\hline II & - & - & - & - & - & - & - & - & 16 \\
\hline III & - & - & + & $-\left(\frac{13}{20}\right)^{*}$ & - & + & - & - & 20 \\
\hline IV & - & - & - & - & + & + & + & + & 25 \\
\hline $\mathbf{v}$ & - & $-\left(\frac{79}{82}\right)$ & + & + & - & + & $+\left(\frac{81}{82}\right)$ & $-\left(\frac{81}{82}\right)$ & 82 \\
\hline VI & - & $-\left(\frac{125}{127}\right)$ & - & - & + & - & - & $+\left(\frac{116}{127}\right)$ & 127 \\
\hline VII & + & $+\left(\frac{\mathbf{4 4}}{55}\right)$ & - & - & $+\left(\frac{54}{55}\right)$ & - & - & $+\left(\frac{\mathbf{3 1}}{\overline{55}}\right)$ & 55 \\
\hline \multirow[t]{2}{*}{ VIII } & + & + & $-\left(\frac{\mathbf{2 7}}{\mathbf{8 1}}\right)$ & $-\left(\frac{\mathbf{2 9}}{\mathbf{3 1}}\right)$ & $-\left(\frac{\mathbf{3 0}}{\mathbf{3 1}}\right)$ & + & $-\left(\frac{26}{29}\right)$ & $-\left(\frac{20}{31}\right)$ & 31 \\
\hline \multirow{2}{*}{\multicolumn{5}{|c|}{ Unclassified organisms }} & \multicolumn{4}{|c|}{ Total number of strains grouped: } & 390 \\
\hline & & & & & & & & & \\
\hline Section 1 & - & - & $+\left(\frac{15}{24}\right)$ & - & - & + & + & $-\left(\frac{\mathbf{2 2}}{\mathbf{2 4}}\right)$ & 24 \\
\hline Section 2 & - & - & $-\left(\frac{10}{11}\right)$ & - & - & + & - & + & 11 \\
\hline Section 3 & - & - & - & - & + & + & - & $+\left(\frac{10}{12}\right)$ & 12 \\
\hline \multirow[t]{2}{*}{ Section 4} & \multicolumn{8}{|c|}{ Miscellaneous reactions } & 15 \\
\hline & \multicolumn{8}{|c|}{$\begin{array}{l}\text { Number of strains classified in Sections: } \\
\text { Total number of strains examined: }\end{array}$} & $\begin{array}{r}62 \\
452\end{array}$ \\
\hline
\end{tabular}

$-=$ negative $++=$ positive.

* Where all strains did not react uniformly, the figures in parentheses show

No. of strains giving the reaction specified No. of strains tested

Organisms of group III.

Seven strains received as $L$. bulgaricus (B8, B 12-B 14, B 18, B21, B 22) as well as seven named strains of $L$. helveticus, L. lactis, and $L$. delbrueckii $\left(\mathrm{H}_{12}\right.$, H13, H 16, H21, L18, L19, D1) were included in group III. Four recently isolated strains (AH41 B, PR 5, PR 8, PR 10) were from Gruyère cheese and presure whilst the remaining two organisms (WL 19, WL 20) in this group were unnamed. The inability to produce gas from citrate was characteristic of all twenty strains. 


\section{Organisms of group IV}

The twenty-five strains: A8-A10, B1, D4, D8, C10, C14, C16, C17, C20, $\mathrm{C} 21, \mathrm{C} 25, \mathrm{H} 2, \mathrm{H3}, \mathrm{H5}-\mathrm{H} 8, \mathrm{H10}, \mathrm{H11}, \mathrm{H} 15, \mathrm{O} 5, \mathrm{O} 9$ and YOG3 constituted group IV. Fifteen were strains received as $L$. casei or $L$. helveticus, nine of which (C14, C16, C17, H2, H5, H6, H7, H8, H15) are believed to be cultures of $L$. casei ATCC 7469. Cultures bearing this collection number were received both as $L$. helveticus and $L$. casei and it is of interest that they all showed similar reactions. Rogosa (1946) suggested that $L$. delbrueckii L.D.5 should be renamed L. casei; two strains of L.D.5 (D4 and D 8) in our collection showed the typical reactions of group IV. Only three freshly isolated organisms were included in this group. Fourteen cultures produced gas from citrate and almost all grew in the presence of $6 \%$ sodium chloride; little resistance was shown to heating at $60^{\circ}$ for 60 or $30 \mathrm{~min}$.

\section{Organisms of group $V$}

The eighty-two cultures in this large group showed thermophilic properties; not only did they grow at $48^{\circ}$, but all survived heating to $65^{\circ}$ for $30 \mathrm{~min}$. and many survived $90 \mathrm{~min}$. at this temperature. Twelve strains of L. lactis (L1, L 3-L 5, L 7-L 10, L 13-L 15, L 17), five of L. leichmannii (LE 2-LE6) and one of $L$. thermophilus (THI) were included as well as A6, B6, B11, D9, H14, H 19, WL 39 and WL 45. All cultures from Gruyère cheese except AH 4, AH5, AH 8B, AH 18B, AH 19B, AH 41 B and AH 53B showed the typical reactions of group V. Other freshly isolated cultures were from pasteurized milk (GORD), présure (PR 2, PR 4, PR 6, PR7, PR 11) and dried stomachs of calves (CS7, CS 8). Three strains (LE 3, LE 4, D9) produced ammonia from arginine, a reaction shown by very few homofermentative lactobacilli.

Bergey's Manual (1948) describes $L$. leichmannii as similar to $L$. delbrueckii but with a lower optimum temperature for growth; it was surprising to find that all strains received as $L$. leichmannii grew at $48^{\circ}$. Only three out of nine strains named $L$. delbrueckii grew at this temperature, one (D9) was classified in group $\mathrm{V}$ and two (D4 and D8) in group IV.

Strains A2 (group I) and A6 (group V) bear the same collection number (NCTC 1899). It is reasonable to suppose that the great differences between the reactions of these two strains may be due to an error in labelling, possibly long-standing, rather than to a mutation during maintenance. Strains AH 10 and PR 6 were somewhat atypical in that the former produced gas from citrate and the latter grew in the presence of $4 \%$ sodium chloride. The survival of L 1 ( $L$. lactis Dorner) at $65^{\circ}$ clearly demanded its inclusion in this group despite its inability to grow at $48^{\circ}$; all other reactions of this organism were typical of the thermophilic lactobacilli (group V).

\section{Organisms of group VI}

Group VI, the largest, contained 127 organisms. Eighteen of these (C1-C9, C11-C13, C18, C22-C24, C26, C29) were received as L. casei and twenty-six (P1-P9, P11, P12, P14-P 26, P30, P31) as L. plantarum. All strains named 
L. arabinosus or L. pentosus as well as the three cultures (CP1-CP3) from New Zealand cheese were in this group. D3, D5, H1, H4, H9, L 18 and five oral strains $(01,03,06,07,011)$ also possessed the typical reactions of the group. Five cultures (E 3, F 5, T7, T8, X3) which, when received, were stated to be heterofermentative, and fifty-five freshly isolated strains from Stilton cheese, silage, raw and sour milk, and fish silage were also classified in group VI.

Few of these strains survived heating at $60^{\circ}$ for even $30 \mathrm{~min}$.; growth was variable in 4 and $6 \%$ sodium chloride, and ten strains grew in the presence of $8 \%$ salt. Gibson \& Abd-el-Malek (1945) observed that one strain of $L$. casei produced gas from citrate, whereas two strains of $L$. plantarum did not. They suggested that examination of large numbers of these strains might provide a means for differentiating $L$. casei from $L$. plantarum. The present work has not confirmed this distinction.

\section{Organisms of group VII}

The fifty-five heterofermentative lactobacilli in group VII include many variously named cultures: $L$. brevis, $L$. buchneri, L. hilgardii, L. pentoaceticus, L. rudensis, L. brassicae-fermentatae, L. lycopersici, L. caucasicus, L. pastorianus, $L$. bifidus, L. acidophil-aerogenes, L. parvus, $L$. frigidus and $L$. malefermentans were all represented. Neither the culture of $L$. caucasicus (CC1) nor the freshly isolated organism from kefir (K1) conformed to the description in Bergey's Manual of the type species of the genus Lactobacillus, but were similar to the Betabacterium caucasicum of Orla-Jensen (1919). Other cultures of recent isolation which were classified in group VII were from beer, Stilton cheese, silage, Jugoslavian sour milk, raw milk, sauerkraut and the bovine rumen. Four strains (SM1 A, S38 A, S40 A, S41 A) isolated from meat and sausages by Niven, Castellani \& Allanson (1949) as well as seven other strains (T 3, BR 28, RM 1, KR 1, SL 48, SL 49, SL 50) in this group were atypical in that they failed to produce ammonia from arginine.

\section{Organisms of group VIII}

Fifteen strains named $L$. fermenti (F 1-F 4, F 6-F 16), two named $L$. gayonii (G1, G2), one named L. mannitopoeus (M1) and thirteen freshly isolated organisms from Gruyère cheese, présure, pig faeces, calf stomach, chick duodenum, the human mouth and raw milk showed the reactions characteristic of group VIII. Only ten strains produced gas from citrate; heat tolerance was variable, some strains failing to survive $30 \mathrm{~min}$. at $60^{\circ}$ and others remaining viable after $90 \mathrm{~min}$. at $65^{\circ}$.

\section{Unclassified organisms}

Section 1. Named strains of $L$. lactis, L. bulgaricus, L. jugurt and $L$. helveticus were among the twenty-four strains in this section. It is of interest that five organisms from the calf abomasum used to supply rennet for the manufacture of Gruyère cheese, and two strains (AH 4, AH5) obtained from such cheese, belonged in this section. Four freshly isolated strains from silage and two from yoghourt were also included. 
Section 2. The eleven cultures in this section (BF 1, BF 3, GF 1, GF 2, N3, N 6, N7, O8, RF 1, P 28, P29) were of oral, faecal or intestinal origin and all save P28 and P29 had been isolated recently. Harrison \& Hansen (1950a) obtained P28 and P29 from the caecal faeces of turkeys and identified them as $L$. plantarum. The characters of the organisms in this section resemble those of strains of $L$. acidophilus included in group I except that growth occurred in the presence of $4 \%$ sodium chloride. It is for this reason alone that the organisms were not included in group $\mathbf{I}$.

Section 3. Strains A7, A 11, C15, C27, C28, C30, D6, D7, O4 and P27 with two freshly isolated cultures, MR 1 and MR3B, formed section 3. P27 was the motile strain of $L$. plantarum described by Harrison \& Hansen (1950b).

Section 4. Section 4 comprised all cultures (15) which could not be included in the groups or sections described above. Only six (S3(1), S3(2), S4, S5, S6 and PF7) of the 452 lactobacilli in the collection showed bifid forms, and vigorous growth of these strains was obtained only when the cultures were incubated anaerobically. The testing of these six strains, five of which (S3(1), S3(2), S4, S5, S6) were received as $L$. bifidus and one (PF7), which was isolated from pig faeces, involved slight modification of the standard methods. Broth media were boiled for $30 \mathrm{~min}$., cooled, inoculated and a 'Vasgarte' seal (Hirsch \& Grinsted, 1953) poured on the surface of the broth. The use of anaerobic jars or similar apparatus was therefore unnecessary. The technique of determining gas production required no modification. Because of the morphological and anaerobic requirements of these six strains, it was considered advisable to include them in section 4 with the unclassified organisms, although some of the bifid organisms possessed reactions similar to those of organisms of group VIII.

\section{DISCUSSION}

The aim of the work described here was the broad division of the genus Lactobacillus into well-defined groups, since this was considered an essential preliminary to the intensive study and complete classification of these organisms. The investigation has resulted in the definition of eight such groups, six of which are homofermentative and two heterofermentative. Three homofermentative groups, I, II and III, though plainly separated from the remaining groups, are not so clearly distinct from each other. The results shown in Table 2 justify the separation of groups I, II and III, but confirmation, probably through the use of additional tests, is required. The similarities found between the reactions of strains of $L$. acidophilus and of $L$. bulgaricus contained in these three groups agree with most of the reports previously published.

The characteristics of some species in the groups described differ considerably from those reported by other workers; this is particularly true of growth temperatures. L. bulgaricus is generally recognized as a thermophilic organism and Orla-Jensen (1919) described one strain which grew at 52.5 ${ }^{\circ}$ although the usual maximum temperature was $50^{\circ}$. One of the differentiating reactions of strains in group II is the failure to grow at $45^{\circ}$ and a representative strain of this group is a named culture, L. bulgaricus NCTC 2889 (B2). 
It is of interest that two strains ( $\mathrm{J}_{1}$ and $\mathrm{J} 2$ ) received as $L$. jugurt, and two freshly isolated strains from yoghourt (YOG 1 and YOG 4) all possess similar characters (see section 1, Table 2) but differ from the organisms included in groups II and III. L. bulgaricus is now considered to be the essential organism in yoghourt (Hiscox, 1951) but, if this be true, J1, J2, YOG 1 and YOG4 should be typical strains of $L$. bulgaricus and the organisms in section 1 would therefore form a 'bulgaricus' group. Strains now in groups II and III would presumably form other groups, not 'bulgaricus', and most of the wellrecognized strains of $\boldsymbol{L}$. bulgaricus, some of which are of historical significance, would then be excluded from a 'bulgaricus' group. It is obvious that many more strains, isolated directly from typical samples of yoghourt, must be studied before this problem is solved.

It is possible that the unclassified thermophilic organisms (including $\mathbf{J ~ 1 , ~ J ~ 2 , ~}$ YOG 1 and YOG 4) in section 1 (Table 2) belong to group V even though differences in heat survival have prevented their inclusion at this stage. The evolution of new tests for the subdivision of group $\mathbf{V}$ should prove profitable as there are indications that three species, $L$. lactis, $L$. thermophilus and $\boldsymbol{L}$. leichmannii, are included therein. The precise taxonomic position and detailed characteristics of $\boldsymbol{L}$. leichmannii are of great importance because of the widespread use of certain strains of this organism in microbiological assays.

Nine named strains of $L$. delbrueckii were tested, and seven of these were classified in five different groups; D1 in group III, D2 in group I, D3 and D5 in group VI, D4 and D8 in group IV, D9 in group V. D 6 and D7 have been included in section 3 of the unclassified organisms. Bergey's Manual states that $L$. delbrueckii grows at $50^{\circ}$, but none of the nine strains tested (except D4, D8 and D9) grew even at $48^{\circ}$. Freshly isolated strains from cereal mash have not yet been examined.

The status of $L$. bifidus is also uncertain. Morphological examination of two strains from the National Collection of Type Cultures (S1 and S2) revealed no branching and these organisms grew well aerobically; they have been classified in group VII. Five further strains of $L$. bifidus (S3(1), S3(2), S4, S5 and S6) and one freshly isolated strain (PF 7) showed bifid forms and grew vigorously only under anaerobic conditions; these have not been classified but are included in section 4 .

The significance of the correlation between the production of gas from glucose and of ammonia from arginine is unknown, but it may be that organisms with both these properties possess a specialized metabolism. Examination of further cultures may indicate that organisms having one or other of these characteristics (e.g. LE3, S38 A) belong to separate groups.

An examination of the morphological and colonial appearances of all strains, recorded under standard conditions, indicated that the differences between the characters of organisms within a given group and of organisms of separate groups were equally variable. At the outset of this work the sugar fermentation reactions of the ninety-five strains originally maintained in the N.I.R.D. collection were determined. Although thirty-one sugars were tested, it has 
not been possible to correlate any of the results with the groupings described in this paper. Morphology, colonial form and sugar fermentation reactions may be of value, however, when the groups have been further subdivided.

All replicate cultures have shown identical reactions in the physiological tests except A2 and A6 which have already been discussed. Duplication and repetition of the tests have given consistent results. The techniques are neither complicated nor in any sense laborious. All media are easily prepared and no elaborate apparatus is required, an accurate water-bath being the only necessary item of specialized equipment. The tests described satisfy therefore the requirements of simplicity, reproducibility and reliability.

The 197 freshly isolated cultures in the collection were obtained from a variety of sources including beer, silage, faeces, milk and cheese. One hundred and seventy $(86.3 \%)$ of these strains have been classified in the eight groups: a further twenty-one fall into the first three sections and only six organisms are included amongst the miscellaneous strains in section 4 . It is of interest that the percentage $(\mathbf{8 6 \cdot 3})$ of freshly isolated cultures classified is identical with the proportion $(86.3 \%$ ) of strains classified in the total collection. The grouping of so high a percentage of freshly isolated strains is of importance. It should now be possible to classify fresh isolations within existing groups, so that the undesirable practice of naming cultures according to their source rather than their characteristics may become less general.

The collection contains no representatives of the type species of the genus, L. caucasicus Beijerinck. Both the strain received as L. caucasicus (CC 1 ) and the organism isolated from kefir (K1) were similar to Betabacterium caucasicum Orla-Jensen, and were classified in group VII. The ambiguity of these names appears to be contrary to Principle 1 of the International Code of Nomenclature (Buchanan, St John-Brooks \& Breed, 1948) and the lack of representatives and detailed description of the type species suggests that the substitution of a recognizable and well-characterized lactobacillus as type species would be advisable. However, it is clear that further intensive study of the genus Lactobacillus is essential before a more suitable type species can be proposed.

Sherman (1937) described the characteristics used in the classification of streptococci and there is much in common between these biochemical tests and those employed in this work. Four tests in particular, namely growth at $10^{\circ}$ and $40^{\circ}$, survival at $60^{\circ}$, production of $\mathrm{NH}_{3}$ and growth in $6.5 \%$ sodium chloride, are almost identical in each case.

The absolute classification of the homofermentative streptococci depends upon a combination of biochemical tests together with serological grouping. The classification of leuconostoc, which may be compared with the heterofermentative lactobacilli, has not been studied in detail. The reactions of the homofermentative lactobacilli resemble in many ways those of the homofermentative streptococci and it may be that a complete classification of the lactobacilli will eventually be based upon both biochemical and serological reactions. Some evidence in this direction has already been obtained. Dr M. Elisabeth Sharpe (personal communication), in preliminary work, has 
succeeded in preparing what appear to be grouping sera for certain species and a high degree of correlation has been found between these serological results and the grouping described in this paper.

The confusion existing within the genus Lactobacillus necessitated the grouping of strains before any given species could be selected for intensive study. This grouping has been accomplished and further investigation and subdivision of each group may now be undertaken. It is hoped that further work will lead to a complete classification of the genus.

I wish to thank Dr A. T. R. Mattick for his advice and guidance, and Mr L. F. Lawes for the preparation of the media. Dr T. Gibson kindly read the manuscript and made valuable suggestions. Thanks are due also to those who sent cultures either to Dr Mattick or to myself.

\section{REFERENCES}

Beijerinck, M. W. (1889). Sur le kéfir. Arch. néerl. Sci. 23. 428.

Briggs, M. (1953). An improved medium for lactobacilli. J. Dairy Res. 20, 36.

Buchanan, R. E., St John-Brooks, R. \& Breed, R. S. (1948). International Bacteriological Code of Nomenclature. J. Bact. 55, 287 reprinted in 1949, J. gen. Microbiol. 3, 444.

Burri, R. \& Kollmann, H. (1941). Studien über die Gattung Thermobacterium (Orla-Jensen) mit besonderer Berücksichtigung der Säuerungsflora des jungen Emmentalerkäses. Landrw. Jb. Schrveiz, 55, 407.

Curran, H. C., Rogers, L. A. \& Whittier, E. O. (1933). The distinguishing characteristics of Lactobacillus acidophilus. J. Bact. 25, 595.

Davis, J. G. (1935). The use of special litmus milk media for the diagnostic culture of lactic acid bacteria. J. Dairy Res. 6, 121.

Friedman, E. \& Black, L. A. (1941). Some characteristics of 'Lactobacillus bifidus' and its relation to Lactobacillus acidophilus. J. Bact. $42,152$.

Grbson, T. \& ABD-EL-Maler, Y. (1945). 'The formation of carbon dioxide by lactic acid bacteria and Bacillus licheniformis and a cultural method of detecting the process. J. Dairy Res. 14, 35.

Grigoroff, S. (1905). Étude sur un lait fermenté comestible. Le 'Kisselo-mleko' de Bulgarie. Rev. méd. Suisse rom. 25, 714.

Hadley, F. P., Bunting, R. W. \& Delves, E. A. (1930). Recognition of Bacillus acidophilus associated with dental caries: a preliminary report. J. Amer. dent. Ass. 17, 2041.

Harrison, A. P. \& Hansen, P. A. (1950a). Lactobacilli from turkeys. J. Bact. 60, 543.

Harrison, A. P. \& Hansen, P. A. (1950b). A motile lactobacillus from the cecal feces of turkeys. J. Bact. 59, 444.

Heinemann, P. G. \& Hefferan, M. (1909). A study of B. bulgaricus. J. infect. Dis. 6, 304.

Hirsch, A. \& Grinsted, E. (1953). Media for the growth and enumeration of anaerobic spore formers from cheese with observations on the effect of nisin. J. Dairy Res. In the Press.

Hiscox, E. R. (1951). A note on yoghourt. Proc. Soc. appl. Bact. 14, xii.

Howe, P. R. \& HATCH, R. E. (1917). A study of the microorganisms of dental caries. Dent. Cosmos, 59, 961.

KulP, W. L. (1929). Preliminary report on a method for the differentiation of L. acidophilus from $L$. bulgaricus. $J$. Bact. 17, 355.

Kulp, W. L. \& Retrger, L. F. (1924). Comparative study of Lactobacillus acidophilus and Lactobacillus bulgaricus. J. Bact. 9, 357. 
McIntosh, J., James, W. W. \& Lazarus-Barlow, P. (1922). An investigation into the aetiology of dental caries. I. The nature of the destructive agent and the production of artificial caries. Brit. J. exp. Path. 3, 138.

McIntosh, J., James, W. W. \& Lazarus-Barlow, P. (1924). An investigation into the aetiology of dental caries. II. The biological characteristics and distribution of B. acidophilus odontolyticus. III. Further experiments on the production of artificial caries. Brit. J. exp. Path. 5, 175.

Morishito, T. (1929). Studies on dental caries, with special reference to aciduric organisms associated with this process. I. Isolation and description of organisms. J. Bact. 18, 181.

Moro, E. (1900). Uber den Bacillus acidophilus. Jb. Kinderheilk. 52, 38.

Niven, Jun., C. F., Smiley, K. L. \& Sherman, J. M. (1942). The hydrolysis of arginine by streptococci. $J$. Bact. 43, 651 .

Niven, Jun., C. F., Castellant, A. G. \& Altunson, V. (1949). A study of the lactic acid bacteria that cause surface discolorations of sausages. J. Bact. 58, 633 .

Orla-Jensen, S. (1919). The lactic acid bacteria. Copenhagen: Andr. Fred. Host and Son.

OrLA-JEnsen, S. (1942). The lactic acid bacteria. 2nd. ed. Copenhagen: Ejnar Munksgaard.

Orla-Jensen, S. (1943). The lactic acid bacteria. Ergänzungsband. Copenhagen: Ejnar Munksgaard.

Oria-Jensen, S., Orla-Jensen, A. D. \& Winther, O. (1935-36). Bacterium bifidum und Thermobacterium intestinale. Zbl. Bakt. 2 Abt. 93, 321.

Pederson, C. S. (1938). The gas-producing species of the genus Lactobacillus. J. Bact. 35, 95.

Pederson, C. S. (1948) in Bergey's Manual of Determinative Bacteriology (6th ed.), p. 349. Ed. by Breed, R. S., Murray, E. G. D. \& Hrtchens, A. P. London: Baillière, Tindall and Cox.

Rahe, A. H. (1918). The classification of the aciduric bacteria. J. Bact. 3, 407 .

Rogosa, M. (1946). Significance in nutritional research of correct identification of Lactobacillus casei, $L$. delbrueckii and $L$. bulgaricus. J. Bact. 51, 575.

Rosebury, T., Linton, R. W. \& Buchbinder, L. (1929). A comparative study of dental aciduric organisms and Lactobacillus acidophilus. J. Bact. 18, 395.

Sherman, J. M. (1937). The streptococci. Bact. Rev. 1, 3.

Sherman, J. M. \& Hodge, H. M. (1940). The value of certain tests in the differentiation of Lactobacillus bulgaricus from Lactobacillus acidophilus. J. Bact. 40, 11.

Shenwood, I. R. (1939). The bacterial flora of New Zealand Cheddar cheese. J. Dairy Res. 10, 426.

ShImwel, J. L. (1948). A rational nomenclature for the Brewery lactic acid bacteria. J. Inst. Brew. 54, 100.

Tissien, H. (1900). Recherches sur la flore du intestinale normale et pathologique du nourisson. Thèse. Université de Paris.

Titrsier, R. P., Geib, D. S. \& Rogosa, M. (1947). Taxonomy of the genus Lactobacillus with special reference to correlations of differential characteristics. J. Bact. 54, 12.

Trttscer, R. P., Pederson, C. S., Snell, E. E., Hendlin, D. \& Niven, Jun., C. F. (1952). Symposium on the lactic acid bacteria. Bact. Rev. 16, 227.

Weaver, R. H. (1932). Fermentation studies on Lactobacillus acidophilus and Lactobacillus bulgaricus. J. infect. Dis. 51, 273.

WeIss, J. E. \& ReTTGER, L. F. (1934). Lactobacillus bifidus. J. Bact. $28,501$. 